\title{
Techniques for Preparation of Cross-Linked Enzyme Aggregates and Their Applications in Bioconversions
}

\author{
Hiroshi Yamaguchi ${ }^{1}$, Yuhei Kiyota ${ }^{2}$ and Masaya Miyazaki ${ }^{2,3, *}$ \\ 1 Liberal Arts Education Center, Tokai University, Kumamoto 862-8652, Japan; yamahiro@tokai-u.jp \\ 2 Department of Applied Chemistry, Graduate School of Engineering, Hokkaido University, Sapporo, \\ Hokkaido 060-8628, Japan; kiyota.y@eng.hokudai.ac.jp \\ 3 Advanced Manufacture Research Institute, National Institute of Advanced Industrial Science and \\ Technology, Tosu, Saga 841-0052, Japan \\ * Correspondence: m.miyazaki@aist.go.jp or m.miyazaki@eng.hokudai.ac.jp; Tel.: +81-11-706-8188
}

Received: 27 March 2018; Accepted: 20 April 2018; Published: 24 April 2018

\begin{abstract}
Enzymes are biocatalysts. They are useful in environmentally friendly production processes and have high potential for industrial applications. However, because of problems with operational stability, cost, and catalytic efficiency, many enzymatic processes have limited applications. The use of cross-linked enzyme aggregates (CLEAs) has been introduced as an effective carrier-free immobilization method. This immobilization method is attractive because it is simple and robust, and unpurified enzymes can be used. Coimmobilization of different enzymes can be achieved. CLEAs generally show high catalytic activities, good storage and operational stabilities, and good reusability. In this review, we summarize techniques for the preparation of CLEAs for use as biocatalysts. Some important applications of these techniques in chemical synthesis and environmental applications are also included. CLEAs provide feasible and efficient techniques for improving the properties of immobilized enzymes for use in industrial applications.
\end{abstract}

Keywords: enzyme; immobilization; cross-linked enzyme aggregates

\section{Introduction}

Enzymes have high catalytic activities and substrate specificities. One single substrate is usually converted to one product. Enzymes are active at modest reaction temperatures, mainly in the range $20-80{ }^{\circ} \mathrm{C}$. These features can reduce the cost per unit of manufactured products. In addition, enzymatic conversions generate less waste than conventional chemical synthetic processes. Synthesis by enzymatic conversion is therefore more energy efficient than chemical synthetic processes. In the last two decades, the use of enzymes in various industries has been continuously increasing. The catalytic and biophysical properties of enzymes, such as catalytic efficiency, substrate specificity, and stability, need to be improved for industrial applications [1,2]. A variety of approaches such as the screening of enzymes from natural sources or random mutations have been used for these purposes [3].

Despite their advantages, several limitations prevent the use of enzymes in industrial applications. Enzymes are proteins with unique three-dimensional structures that are essential for their catalytic activity. Because they often have low operational stability, exposure to high temperatures or organic solvents can denature enzymes, leading to loss of catalytic activity. Modern protein engineering techniques can improve the catalytic and biophysical properties of some, but not all, enzymes with potential industrial uses. Immobilized enzymes provide one solution to these difficulties. They have several advantages [2,4-6]. An enzyme can be immobilized at high concentrations on the carrier material, resulting in a high concentration of catalyst in the reaction system. Consequently, catalytic reactions can be performed rapidly. The operational stability and reusability of immobilized enzymes 
are reported to be higher than those of free enzymes. Furthermore, because enzymes immobilized on carrier materials are insoluble catalysts, they can be easily separated and removed from reaction vessels.

Recently, various enzymes immobilized on carrier materials such as modified glass or polymethyl methacrylate have been developed for industrial use [7,8]. Enzyme immobilization is usually achieved by chemical covalent linking, affinity labeling, physical adsorption, or entrapment. These immobilization methods have been described in recent reviews [5-8]. Adsorption is a simple and low-cost method. Enzyme immobilization by this method can provide high retention of enzymatic activity. However, adsorbed enzymes are likely to leak gradually from the carrier materials, therefore the operational stability is lower than that provided by covalent linking. For covalent or noncovalent linking methods, surface modification of the carrier materials is generally necessary to improve the operational stability. Noncovalent binding is often achieved by affinity interactions such as that between a histidine-tagged enzyme and metal-ion-chelated beads $[9,10]$. Although the interaction is specific, it requires the use of recombinant tagged enzymes. This method is therefore unsuitable for routine immobilization of all other enzymes. In contrast, covalent linking methods involve chemical reactions between the side-chains in enzymes and surface-modified carrier materials. These methods do not require any modification of the target enzymes. However, it requires expensive surface-modified carrier materials. Furthermore, multiple reaction points often alter the three-dimensional structure of the enzyme, leading to loss of activity and operational stability [11,12]. In addition, the reported procedures for preparing immobilized enzymes are usually multistep procedures. Facile techniques for routine immobilization of enzymes are therefore needed.

Enzyme cross-linking, in which enzymes are covalently connected to each other by cross-linkers, can be partly categorized as covalent linking. This method enables the formation of miniature structures that consist of polymerized enzymes. Cross-linked enzyme aggregates (CLEAs) have recently been prepared for use in carrier-free enzyme-immobilization methods [2,4]. They are easily prepared, and carrier costs are circumvented. The prepared CLEAs showed good retention of catalytic activity, high operational stability, and reusability [4]. Improvement of the biophysical properties can significantly reduce the cost of enzymes and this makes industrial applications economically feasible. In this review, we specifically introduce recent advances in CLEA techniques for industrial applications. Typical and modified methods for CLEA preparation are summarized. The coimmobilization of two or more enzymes is also covered. Finally, the use of CLEA reactors for chemical synthesis and environmental applications is introduced.

\section{Cross-Linking Enzyme Immobilization}

Cross-linked enzymes were first reported in the 1960s [13], but were never popular because they were generally difficult to handle. In addition, they showed low catalytic activities and low operational stabilities. In the 1990s, cross-linked enzyme crystals were prepared for use as biocatalysts [14, 15]. Although the method was applicable to a wide variety of enzymes and cross-linked enzyme crystals showed excellent operational stabilities, highly purified enzymes were needed for protein crystallization. In contrast, CLEA preparation involves simple precipitation (physical aggregation) of the enzymes from an aqueous buffer with a precipitant (a salt, an ionic/nonionic polymer, or an organic solvent) instead of crystallization. Aggregation (precipitation) of enzymes induced by addition of a precipitant to an aqueous solution of enzymes is commonly used in traditional protein purification. Physical aggregation of enzyme molecules into microstructures can be induced without denaturation of the enzyme's three-dimensional structure by addition of a precipitant. Chemical cross-linking of the aggregated enzymes produces CLEAs. This improved enzyme immobilization method is simple and does not require highly purified enzymes.

\subsection{General Preparation of CLEAs}

A typical procedure for the preparation of CLEAs is shown in Figure 1a. CLEAs are generally prepared by aggregating an enzyme by addition of a precipitant such as $\left(\mathrm{NH}_{4}\right)_{2} \mathrm{SO}_{4}$ or $t$-butanol, 
and then cross-linking with a cross-linker such as glutaraldehyde [16]. Cross-linking occurs between lysine (Lys) residues on the surfaces of neighboring enzyme molecules and glutaraldehyde via a Schiff's base reaction. This procedure is simple and can be widely applied. Every enzyme has a unique primary structure (amino acid sequence) and surface structure (the number of accessible Lys residues), therefore the preparation of CLEAs can be optimized, as described below.

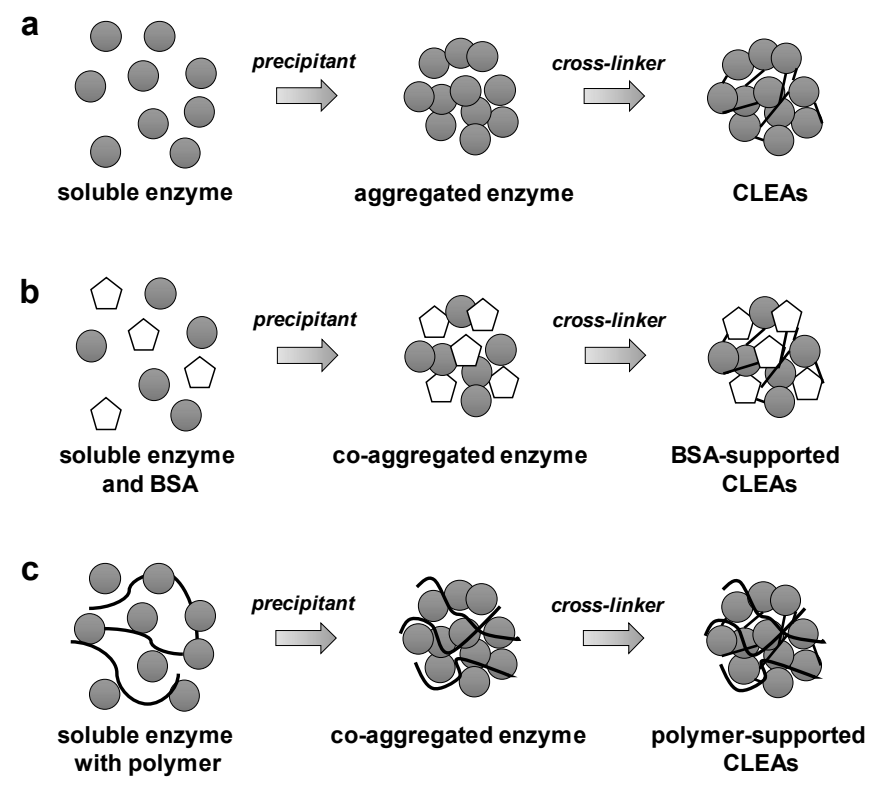

Figure 1. Preparation of CLEAs. (a) General cross-linking method [4]; (b) bovine serum albumin (BSA)-supported CLEA cross-linking method. Combined (combi)-CLEAs are prepared by similar processes (see Section 3); (c) ionic-polymer-supported CLEA cross-linking method.

\subsection{Optimization by Additives}

\subsubsection{Bovine Serum Albumin (BSA)}

Shah et al. reported that addition of BSA facilitates CLEA preparation when the enzyme concentration is low and/or the enzymatic activity is affected by the high concentration of glutaraldehyde that is required to obtain aggregation [17]. The preparation of CLEAs with BSA is shown in Figure 1b. In this study, lipase-CLEAs and penicillin acylase-CLEAs were prepared. The lipase-CLEAs that were prepared with BSA showed 100\% activity, whereas CLEAs without BSA did not retain their activity because little insoluble aggregate was obtained at low enzyme concentrations. Similar results were observed in the case of penicillin acylase-CLEAs. Scanning electron microscopy showed that the CLEAs that were prepared with BSA were less amorphous and had a similar morphology to those of other reported CLEAs [18]. Recently, it was reported that lipase-CLEAs prepared optimally with BSA resisted lipase deactivation by acetaldehyde, which occurs by transacetylation between benzyl alcohols and vinyl acetate [19]. The CLEA structure consists of networks of cross-linked lipase and BSA, and this prevents access of acetaldehyde to the important amino acid residues of lipase.

\subsubsection{Ionic Polymer}

As described above, cross-linking typically requires activation of a Lys residue on the enzyme surface with the aldehyde groups of a cross-linker that can react readily with other Lys residues of the enzyme. The cross-linking efficiency depends on the number of surface Lys residues. An acidic or neutral enzyme with a low content of Lys residues therefore cannot be cross-linked efficiently merely 
by using a cross-linker. Although a high concentration of cross-linker can increase the cross-linking efficiency, this often causes a conformational change, leading to loss of enzymatic activity [20].

To overcome this problem, coaggregation of enzymes and ionic polymers (Figure 1c) was investigated [21-23]. López-Gallego et al. reported that glutaryl acylase, with a low content of Lys residues, was efficiently cross-linked by coaggregation with the aminated polymer polyethylenimine (PEI) [21]. Glutaryl acylase-CLEAs retained more than $60 \%$ of their initial activity, and the thermal stability of the immobilized enzyme was improved. The same research group also prepared penicillin acylase-CLEAs by coaggregation with PEI. The stability of these CLEAs in organic media was high [22]. Enzymatic reactions in organic media are important in industry. Zhang et al. prepared trehalose synthase-CLEAs by coaggregation with PEI [23]. They showed that coimmobilization with PEI enhanced the cross-linking efficiency even at low concentrations of the enzyme. Recently, metal-ion-chelated PEI was used for immobilization of a multimeric oxidoreductase (glycerol dehydrogenase). The CLEAs formed were stabilized by hydrogen bonding, electrostatic forces, and coordination bonding [24]. Although a cross-linker was not used to immobilize the enzyme in this study, nanoparticles of diameter $250-650 \mathrm{~nm}$ were obtained. The operational stability and catalytic activity were enhanced. This strategy of cross-linking enzymes with modified PEI has potential applications in the immobilization of multimeric enzymes.

Our group developed a facile and inexpensive method for preparing an enzyme-immobilized reactor via an enzyme cross-linking reaction. Enzyme immobilization was achieved by the formation of a polymeric membrane of enzyme molecules on the inner wall of a polytetrafluoroethylene tube through cross-linking aggregation under laminar flow [25] (Figure 2a). The aggregated enzyme membrane was based on CLEAs prepared with glutaraldehyde as a cross-linker. This method for the preparation of a CLEA-based enzyme microreactor (CEM) is unsuitable for electronegative enzymes because the relative paucity of amino groups results in inefficient CLEA formation. To extend the generality of CEM preparation, we developed an improved method with poly-Lys as an aggregation booster to achieve effective aggregation of acidic enzymes [26] (Figure 2b). CEM preparation can be used for immobilization of a broad range of functional enzymes. These methods have been used to develop several enzymatic microfluidic systems [27-30]. In addition, the operational stability of enzymes in CLEAs formed by coaggregation with poly-Lys was examined [31]. Two proteases (chymotrypsin and subtilisin), an oxidase (laccase), and a multimeric enzyme (citrate synthase), which have diverse three-dimensional structures and catalytic activities, were used as model enzymes. Compared with the free enzymes, these four CLEAs were more stable at high temperatures, in the presence of a chemical denaturant, or in an organic solvent. They were recycled without appreciable loss of activity. As in the case of coaggregation with PEI, poly-Lys-supported immobilization is also applicable to multimeric enzymes [31].

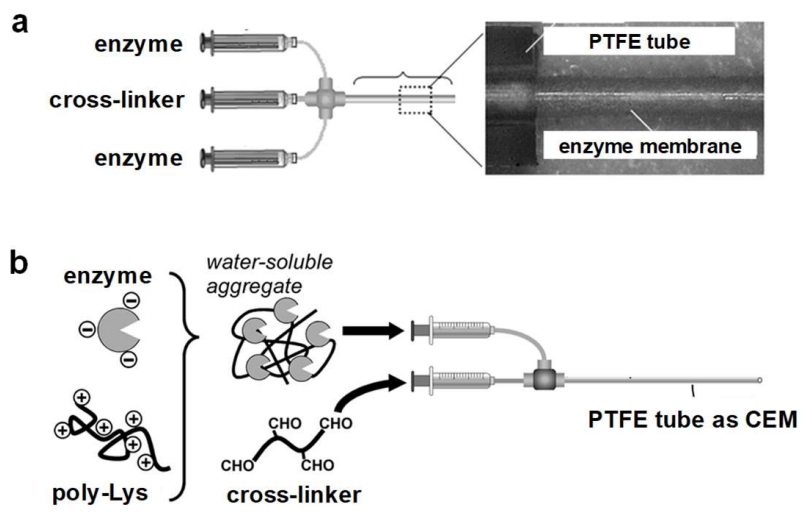

Figure 2. Preparation of CLEAs on inner wall of polytetrafluoroethylene (PTFE) tube by cross-linking aggregation under laminar flow: (a) general cross-linking method [25] and (b) poly-Lys-supported cross-linking method [26]. CEM: CLEA-based enzyme microreactor. 


\subsubsection{Surfactants}

The activation of enzymes with additives such as surfactants or amines is well known [32]. On the basis of this property of enzymes, a surfactant (SDS, Triton X-100, or Tween 80) was added during the preparation of lipase-CLEAs [33-35]. The CLEAs showed a two-fold or greater increase in catalytic activity when SDS was present during CLEA preparation [33]. Such enhanced activity of lipase-CLEAs by other surfactants has been reported [34]. These surfactants were added at the aggregation step and initiated binding to the hydrophobic active sites of the enzyme. It has been proposed that the enzyme forms open active sites by interactions with the surfactant. The open active sites can produce hyperactive CLEAs. It is assumed that the surfactants can be washed out of the active sites after the cross-linking reaction [35].

\subsubsection{Cations}

Amylase is a metal-ion-dependent enzyme. Calcium and sodium ions are reported to increase the activity of $\alpha$-amylase [36]. Thermostable $\alpha$-amylase-CLEA preparation by a cation-assisted strategy was recently reported [37]. The aggregation and cross-linking of $\alpha$-amylase were performed in a cation-enriched nonaqueous environment. The addition of calcium and sodium ions at the optimum ratio gave $\alpha$-amylase-CLEAs with increased activity and operational stability [37].

\subsection{Optimization by Precipitant Selection}

Because aggregation and precipitation of enzymes are induced by addition of a precipitant, precipitant selection is important for optimization [18]. The type of precipitant used to prepare CLEAs varied and the operational stabilities of the CLEAs differed, but the same enzyme was used in the studies described. Khorshidi et al. reported that cellulase-CLEAs produced using saturated $\left(\mathrm{NH}_{4}\right)_{2} \mathrm{SO}_{4}$ lost $70 \%$ of their activity after one cycle [38]. Several cellulase-CLEAs produced using organic solvents showed better activities and reusability [39,40]. Recently, a systematic study of the effects of different precipitants and various cross-linking parameters was reported [41]. The effects of different precipitants, namely $\left(\mathrm{NH}_{4}\right)_{2} \mathrm{SO}_{4}$, poly(ethylene glycol) (PEG), and $t$-butanol, on the resolubilized enzyme activity and final CLEA activity were examined. Cellulase-CLEAs prepared with PEG retained high activity. The activity of cellulase-CLEAs prepared with $\left(\mathrm{NH}_{4}\right)_{2} \mathrm{SO}_{4}$ was lower than that of cellulase-CLEAs produced with PEG. The CLEAs prepared with $t$-butanol were inactive [41]. Similar results were reported in the case of lipase-CLEAs. Lipase-CLEAs were prepared with four types of precipitant, namely acetone, PEG 200 and 600 , and $\left(\mathrm{NH}_{4}\right)_{2} \mathrm{SO}_{4}$. The CLEAs precipitated with PEG and saturated $\left(\mathrm{NH}_{4}\right)_{2} \mathrm{SO}_{4}$ had superior catalytic activities [42]. Enzymes precipitated with water-miscible and water-immiscible solvents showed decreased activities [18]. The yield of CLEAs greatly depends on the type of precipitant and microbial source. It is hypothesized that lipases from different sources have different glycosylated surfaces, and this may result in different biophysical properties. The aggregation and packing of the enzyme molecules may be affected by the precipitant.

\subsection{Optimization by Cross-Linker}

The cross-linker forms covalent bonds between Lys residues on the enzyme surface, and the CLEAs formed are permanently insoluble. Glutaraldehyde is commonly used as a cross-linker. Excess glutaraldehyde can bind to amino acid residues during cross-link formation. If the catalytically essential residues react with glutaraldehyde, the catalytic activity of the CLEAs will be reduced. The use of mild cross-linkers instead of glutaraldehyde is therefore essential to overcome the drawbacks associated with traditional cross-linking reactions.

Based on this idea, ethylene glycol bis(succinimidylsuccinate) (EG-NHS) was proposed as an alternative cross-linker for the preparation of lipase-CLEAs (EGS-CLEAs). The operational stability and reusability of EGS-CLEAs were compared with those of lipase-CLEAs formed using glutaraldehyde [43]. The hydrolytic and esterification activities of the EGS-CLEAs were better than 
those of the glutaraldehyde aggregates. Both CLEAs showed similar thermal and operational stabilities. These results indicate that EG-NHS could be used as a mild cross-linker in the preparation of CLEAs instead of glutaraldehyde. This strategy can be extended to the preparation of CLEAs of other enzymes.

\subsection{Novel Method for Preparation of CLEAs}

\subsubsection{CLEA Particle Size}

Because most CLEAs are prepared in solution, the particle size and cross-linking efficiency may not be uniform. Large particles may result in diffusion constraints and low catalytic efficiency, and tiny clusters have poor recoverability [18]. CLEAs that consist of small particles cannot be filtered off or recycled. Control of the CLEA particle size and a uniform size distribution are therefore essential to overcome these drawbacks. To address these problems, a new method for preparing trehalose synthase-CLEAs in a water-in-oil emulsion instead of in solution was developed [44]. This method involves precipitation of an enzyme in solution, and then mixing the aqueous phase with an oil phase to form a water-in-oil emulsion. Cross-linking was performed within the emulsion droplets. CLEAs prepared by this emulsion-based method rather than the conventional method were spherical. The CLEAs had a ball-like structure and were of diameter 20-60 $\mu \mathrm{m}$. These CLEAs were easily separated from the reaction mixture. As expected, the operational stability of the spherical CLEAs was higher than that of the free enzyme.

Nguyen et al. reported the preparation of uniform cellulase-CLEAs by using a millifluidic reactor. The reactor had two inlets and a Y-junction that can control the mixing pattern of the enzyme and precipitant solutions [40]. The particle size of the cellulase-CLEAs can be strictly controlled between 200 and $400 \mathrm{~nm}$ by controlling the concentrations of the precipitant and cross-linker and the flow rates. The activity of the cellulase-CLEAs was more stable than that of the free enzyme at high temperatures.

\subsubsection{Molecular-Imprinted CLEAs}

Molecular imprinting enhances the catalytic activity by increasing electrostatic interactions and hydrogen bonding between the surface residues on enzymes $[45,46]$. It has been suggested that the lid that covers the active site of an enzyme can be opened at the interface in the presence of imprinting molecules [45]. This mechanism resembles the concept of the approach that uses additives to improve the CLEA properties, as described in Section 2.2.3. Recently, the advantages of molecular imprinting of CLEAs were investigated. Hydroxynitrile lyase-CLEAs prepared with 2-butanone as a molecular-imprinting additive showed improved activity [47]. Winter et al. used $\alpha$-glucosylglycerol to prepare sucrose phosphorylase-CLEAs and reported that the enzymatic performance was better than those of nonimprinted CLEAs and the free enzyme in solution [48]. Similarly, lipase-CLEAs immobilized by molecular imprinting showed improved thermal stability, hydrolytic efficiency, and reusability [49].

\subsection{Carrier-Bound CLEAs}

The particle sizes of the majority of reported CLEAs are less than $10 \mu \mathrm{m}$ [50]. As described in Section 2.5.1, CLEAs of small particle size are difficult to separate and recover from the reaction system. This can result in problems in the continuous use of CLEAs. To overcome this problem, some researchers recently investigated carrier-bound CLEAs to develop biocatalysts with good mechanical stabilities.

\subsubsection{CLEAs in Silica Material}

$\alpha$-Chymotrypsin-CLEAs and lipase-CLEAs formed by cross-linking into hierarchically ordered mesoporous silica have been reported [51]. $\alpha$-Chymotrypsin-CLEAs showed high enzyme immobilization efficiency and significantly increased enzyme stability. However, the mesoporous silica pore size was small, which limited the maximum immobilization of CLEAs. To improve the 
immobilization yield, a simple strategy for preparation of CLEAs by one-step cross-linking into the pores of macroporous silica gel was developed [52]. Macroporous silica gel is usually used as a carrier material because it has controlled porosity and a high surface area. Papain-CLEAs in macroporous silica gel showed good storage and thermal stabilities. Moreover, papain-CLEAs showed good reusability because the CLEAs were of appropriate size. Cui et al. reported that the formation of phenylalanine ammonia lyase-CLEAs in the pores of mesoporous materials also gave a high loading yield of the enzyme, and good operational stability and activity retention [53]. Recently, lipase-CLEAs in three-dimensionally ordered macroporous silica materials $\left(3 \mathrm{DOM} \mathrm{SiO}_{2}\right)$ were developed [54]. Lipase was precipitated in the pores of $3 \mathrm{DOM} \mathrm{SiO}_{2}$ before cross-linking with glutaraldehyde. Compared with free lipase, lipase-CLEAs in $3 \mathrm{DOM} \mathrm{SiO}_{2}$ showed excellent thermal and mechanical stability. Improved activity and reusability were also achieved.

\subsubsection{Magnetic CLEAs}

Use of a magnetic field is a simple method for the separation and recovery of magnetic materials. Magnetic $\alpha$-amylase-CLEAs were prepared by addition of magnetite nanoparticles (MNPs) with $\mathrm{NH}_{2}$-functionalized surfaces to an enzyme solution [55]. In the case of magnetic CLEAs, $100 \%$ of the $\alpha$-amylase activity was recovered, whereas only $45 \%$ recovery was achieved in the case of nonmagnetic CLEAs because of the low content of Lys residues of amylase. The optimum operating temperature of the magnetic CLEAs was better than those of the free enzyme and nonmagnetic CLEAs. The magnetic CLEAs also had enhanced thermal and storage stabilities. Furthermore, because of the magnetic properties of the nanoparticles, magnetic $\alpha$-amylase-CLEAs can be easily separated from the reaction mixture without centrifugation or filtration [55]. Sekhon et al. prepared magnetic cutinase-CLEAs for degradation of polycaprolactone (PCL) [56]. The CLEAs retained 55\% activity after 50 cycles; therefore, enzymatic degradation of PCL with CLEAs is a good strategy.

In most cases, modification of the MPN surfaces is required, both for stabilization of the magnetic fluid and for introduction of functional groups. Cellulase-CLEAs on $\mathrm{NH}_{2}$-functionalized $\mathrm{Fe}_{3} \mathrm{O}_{4} @$ silica core-shell MNPs have been reported [38]. Separation of the magnetic cellulase-CLEAs from the reaction system was simple, and their thermal and operational stabilities were better than those of the free enzyme. Liu et al. prepared magnetic lipase-CLEAs by immobilization of lipase-CLEAs on magnetic particles. To improve immobilization, a large number of amino terminal groups were introduced by using $p$-benzoquinone as the cross-linker [57]. $p$-Benzoquinone reacts with the amino or hydroxyl groups of the enzyme and $\mathrm{NH}_{2}$-groups on the MNPs, to form stable magnetic CLEAs by formation of $\mathrm{C}-\mathrm{O}$ and $\mathrm{C}-\mathrm{N}$ bonds. It is suggested that this improved immobilization method could prevent gradual release of the enzyme from CLEAs and/or MNPs. As expected, the magnetic lipase-CLEAs showed improved immobilization efficiency, activity, and reusability, compared with nonmagnetic CLEAs. The magnetic CLEAs efficiently resolved $(R, S)$-2-octanol and retained $100 \%$ activity with $100 \%$ enantioselectivity [57].

\subsubsection{Entrapment CLEAs in Alginate Beads}

Enzyme entrapment in alginate beads is a popular immobilization method. However, the enzyme often leaks from the alginate beads during enzymatic reactions because enzymes are usually smaller than the pore size of alginate beads $(\sim 200 \mathrm{~nm})$. Because the CLEA size is generally 1-10 $\mu \mathrm{m}$, entrapment of CLEAs in alginate beads can solve leakage problems $[4,16]$. In addition, the alginate beads can be easily separated by simple filtration. $\mathrm{Xu}$ and Yang reported the entrapment of tyrosinase-CLEAs. The CLEAs in alginate beads retained 100\% activity after six cycles [58]. Nguyen et al. reported that cellulase-CLEAs in alginate beads had good operational stability and leakage of cellulase was prevented [59]. 


\section{Coimmobilization of Two or More Enzymes in CLEAs}

A new concept, that is, CLEAs with various catalytic activities within a single CLEA particle, has been developed. In this section, combined CLEAs (combi-CLEAs) and multipurpose CLEAs (multi-CLEAs) are introduced.

\subsection{Combi-CLEAs}

Multistep chemical syntheses usually require several procedures such as the separation of intermediates. Combined CLEAs (combi-CLEAs) were introduced for one-pot chemical synthesis [2,4]. Combi-CLEAs with (S)-hydroxynitrile lyase, nitrilase, and penicillin $\mathrm{G}$ amidase were prepared and used to catalyze one-pot synthesis of (S)-mandelic acid from benzaldehyde. A good yield ( $90 \%)$ and enantiomeric excess (99\%) were achieved, with complete benzaldehyde conversion [60]. Combi-CLEAs consisting of $\alpha$-amylase, glucoamylase, and pullulanase were prepared and used to catalyze one-pot starch hydrolysis [61]. Combi-CLEAs, a separate CLEA mixture, and a free enzyme mixture gave $100 \%$, $60 \%$, and $40 \%$ conversions, respectively, in one-pot starch hydrolysis. The enzymes in combi-CLEAs were reported to be thermally stable. In addition, the combi-CLEAs retained $100 \%$ catalytic activity after five cycles.

Combi-CLEAs have also been used in bioethanol production from lignocellulosic biomass. Periyasamy et al. prepared combi-CLEAs of xylanase, cellulase, and $\beta-1,3$-glucanase for this purpose [62]. The thermal and storage stabilities of the CLEAs were better than those of the free enzymes. The recovered combi-CLEAs retained $90 \%$ activity for six cycles. Combi-CLEAs hydrolyzed about $84 \%$ of ammonia-cooked sugarcane bagasse (SCB) in $48 \mathrm{~h}$, whereas the free enzymes gave a maximum hydrolysis of $73 \%$,

Combi-CLEAs of ketoreductase and D-glucose dehydrogenase were used for the regeneration of dihydropyridine nucleotide cofactors in the synthesis of valuable chiral alcohols [63]. The CLEAs showed high activity, long-term operational stability, and reusability. A prochiral keto ester was used in the synthesis of a key atorvastatin intermediate. Combi-CLEAs catalyzed the enantioselective reduction of the prochiral keto ester with high activity and selectivity. More recently, magnetic combi-CLEAs containing ketoreductase and D-glucose dehydrogenase were developed [64]. Magnetic combi-CLEAs showed an optimum temperature, thermal stability, and optimum $\mathrm{pH}$ similar to those of combi-CLEAs. Magnetic combi-CLEAs also showed more efficient activity and better operational stability in both aqueous and biphasic systems than did nonmagnetic combi-CLEAs. Furthermore, the magnetic CLEAs can be recovered with a magnetic field during multiple use.

Cascade reactions that involve unstable intermediates are often found in biological systems. Nguyen et al. prepared combi-CLEAs of glucose oxidase and horseradish peroxidase (HRP) and used them to catalyze a cascade reaction in which hydrogen peroxide is formed as an unstable intermediate [65]. The CLEAs were effective even in the presence of catalase, which rapidly catalyzes the decomposition of hydrogen peroxide. Because of the short diffusion distance between glucose oxidase and peroxidase in the combi-CLEAs, the intermediate hydrogen peroxide was not efficiently decomposed by catalase [65].

Recent studies have investigated pharmaceutical applications of combi-CLEAs. Trehalose has many applications in the food, pharmaceutical, and cosmetic industries. Park et al. reported the production of trehalose from sucrose in a one-pot synthesis using combi-CLEAs of sucrase, trehalose synthase, and trehalose hydrolase [66]. Scism and Bachmann reported five-enzyme combi-CLEAs of ribokinase, phosphoribosyl pyrophosphate synthetase, engineered hypoxanthine phosphoribosyl transferase, adenylate kinase, and pyruvate kinase for use in the cascade synthesis of nucleotide analogs [67]. 


\subsection{Multi-CLEAs}

Dalal et al. developed a single multipurpose biocatalyst that was based on multi-CLEAs containing pectinase, xylanase, and cellulase [39]. These CLEAs were designed to catalyze three different and independent reactions. The obtained multi-CLEAs were more thermostable than the free enzymes. All three enzymes in the multi-CLEA were reusable and showed no loss of activity after three cycles. Mahmod et al. prepared multi-CLEAs containing lipase and protease from fish viscera [68]. The multi-CLEAs were used to catalyze two reactions. The stain-removing ability of commercial detergents during washing was improved by $68 \%$ by addition of multi-CLEAs. Protease in multi-CLEAs was used to catalyze biodiesel production from vegetable oil. These results indicate that the use of multi-CLEAs is a promising technique for biotechnological applications. Neutrase and papain were coimmobilized in CLEAs and their properties were investigated [69]. The thermal and $\mathrm{pH}$ stabilities of the multi-CLEAs were clearly better than those of the free enzymes. In addition, the multi-CLEAs retained relatively high activities in nonpolar and hydrophilic solvents, and no loss of activity occurred during storage at $4{ }^{\circ} \mathrm{C}$ for more than six months. The activities of multi-CLEAs in bean protein and zein hydrolysis were better than those of the free enzymes. These results show that multi-CLEAs have a wide range of industrial uses as a multifunctional catalyst.

\section{Application for Processing by CLEAs}

As described above, enzyme immobilization by CLEA formation is a simple and useful technique. The three-dimensional structure of the enzyme in CLEAs is conserved, therefore its catalytic activity is retained. Moreover, CLEAs have several advantages such as insolubility and superior operational stability. The use of CLEAs as biocatalysts in various industries is therefore continuously increasing. In this section, we introduce recent applications of CLEA techniques, especially in chemical synthesis and environmental applications.

\subsection{Chemical Synthesis}

\subsubsection{Pharmaceutical Chemicals}

$(-)-\gamma$-Lactam is an essential building block in the synthesis of carbocyclic nucleosides, which have potent antiviral activities because of their inhibitory activity against viral reverse transcriptase. $(+)-\gamma$-Lactamase can catalyze the conversion of only $(+)-\gamma$-lactam in a racemic mixture, suggesting that $(-)-\gamma$-lactam can be recovered from the reaction mixture by a simple reaction. Modified CEMs packed with $\gamma$-lactamase-CLEAs combined with pore-glass particles have been reported [70]. The thermophilic $\gamma$-lactamase-CLEAs retained $100 \%$ of their initial activity and retained $52 \%$ activity after $10 \mathrm{~h}$.

$\alpha$-Cyanohydrins are key building blocks in the pharmaceutical and agrochemical industries. Hydroxynitrile lyase from Davallia tyermannii (DtHNL) catalyzes the enantioselective synthesis of $\alpha$-cyanohydrins. DtHNL-CLEAs were prepared [71] and showed enhanced stability under acidic conditions. The DtHNL-CLEAs were used for ( $R$ )-mandelonitrile synthesis ( $99 \%$ conversion, $98 \%$ ee) in a biphasic system, and evaluated for use in the synthesis of $(R)$-hydroxypivaldehyde cyanohydrin.

We developed a microreaction system for the optical resolution of racemic amino acids [27]. This system was based on a continuous microfluidic system consisting of acylase-CEM (see Section 2.2.2) and a microextractor. Acylase-CEM showed high enantioselectivity for racemic amino acids or amino acid derivatives. The microextractor supplied a laminar flow of two immiscible solutions and selectively extracted (separated) the products. This microfluidic system could be used for efficient continuous production of optically pure chemical compounds.

L-3,4-Dihydroxyphenylalanine (L-DOPA) is used to treat Parkinson's disease. Tyrosinase-CLEAs catalyzed the conversion of tyrosine to L-DOPA [72]. A conversion yield of $53 \%$ was obtained in $2 \mathrm{~h}$, with a productivity of $209 \mathrm{mg} \mathrm{L}^{-1} \mathrm{~h}^{-1}$. This result is much better than those reported for batch processes that used tyrosinase immobilized on carrier materials. The operational stability of the CLEAs was improved by entrapment in alginate beads. A continuous stirred-tank reactor with 
entrapped CLEAs in alginate beads achieved good mechanical stability (a long lifetime of $>104 \mathrm{~h}$ ) and a productivity of $57 \mathrm{mg} \mathrm{L}^{-1} \mathrm{~h}^{-1}$.

Peptide synthesis with enzymes is a potentially cost-efficient technique. However, there are some limitations to the synthesis of peptides with sterically hindered structures or noncoded amino acids. Lipase-CLEA- and alcalase-CLEA-mediated peptide syntheses have been reported [73]. To enable specific recognition by the enzymes, special ester moieties, that is, guanidinophenyl, carboxamidomethyl (Cam), and trifluoroethyl (Tfe) esters have been used. The Cam and Tfe esters enable alcalase-CLEA-catalyzed synthesis of peptides with sterically hindered structures and noncoded acyl donors. Although chemical synthesis of these special esters is usually difficult, they can be efficiently synthesized by using lipase-CLEAs or alcalase-CLEAs. These results suggest that ester synthesis by lipase-CLEAs and subsequent peptide synthesis by alcalase-CLEAs can be performed simultaneously in a one-pot approach.

\subsubsection{Polymers}

Synthetic polyamides have high mechanical strength and good thermal resistance and are widely used in industrial applications. The industrial synthesis of these polymers usually involves a melting process. Because of the high melting temperatures and relatively low decomposition temperatures of polyamides with aliphatic-aromatic structures, the synthesis of polyamides by melting processes is usually difficult. Cutinase-CLEA-catalyzed synthesis of oligoamides with aliphatic-aromatic structures overcomes this difficulty [74]. Although a commercially available immobilized lipase gave a higher conversion efficiency than cutinase-CLEAs, the CLEAs achieved the highest degree of polymerization in the one-step or two-step synthesis of oligo( $p$-xylylene sebacamide).

\subsubsection{Nanoparticles}

Silver nanoparticles are the focus of much research because of their catalytic, antimicrobial, and optical properties. The synthesis of silver nanoparticles by conventional methods is energy- and capital-intensive and is environmentally unfriendly because of the use of toxic solvents or additives that are difficult to dispose of and degrade on industrial scales. Moreover, silver nanoparticles synthesized by these conventional methods cannot be used for in vivo biomedical applications because the toxic chemicals from the synthetic process are incompatible with biological systems. To overcome these problems, nicotinamide adenine dinucleotide (NADH)-dependent nitrate reductase-CLEAs were developed for the synthesis of silver nanoparticles from silver nitrate [75]. The CLEAs catalyzed reduction of silver ions to silver nanoparticles at neutral $\mathrm{pH}$. NADH and 8-hydroxyquinoline were used as an electron source and an electron shuttle, respectively. The size of the obtained silver nanoparticles was strictly controlled between 5 and $7 \mathrm{~nm}$. In addition, these CLEAs showed $80 \%$ catalytic recovery after five cycles, indicating that they have good operational stability.

\subsection{Environmental Purposes}

\subsubsection{Decolorization and Detoxification of Dyes}

For environmental protection, the textile, dyeing, printing, and related industries should dispose of or treat synthetic dye-contaminating wastewater. The use of enzymes potentially enables the efficient and low-cost degradation of pollutants and has therefore been investigated for the treatment of wastewater. One of the examined enzymes, laccase, is widely used for catalytic degradation in the treatment of industrial wastewater [76]. Kumar et al. reported the degradation and detoxification of synthetic dyes by magnetic laccase-CLEAs [77]. The magnetic laccase-CLEAs showed good thermal and operational stabilities. Laccase-CLEAs $\left(0.2 \mathrm{U} \mathrm{mL}^{-1}\right)$ rapidly degraded $61-96 \%$ of synthetic dyes (initial concentration of $50 \mathrm{mg} \mathrm{L}^{-1}$ ) such as Remazol brilliant blue R, malachite green, and Reactive Black 5 at $20^{\circ} \mathrm{C}$ and $\mathrm{pH} 7.0$. 
HRP-CLEAs were prepared and their biocatalytic efficacy in biodegradation was investigated [78]. The immobilization efficiency was improved by cross-linking HRP with EG-NHS (see Section 2.4). Dye degradations were performed in a CLEA-packed reactor. Methyl orange degradation of $94 \%$ was observed within the shortest treatment time. The CLEA reactor system was also used to treat other dyes ( $92 \%$ of Basic red $9,84 \%$ of indigo, $82 \%$ of rhodamine B, and $74 \%$ of rhodamine $6 \mathrm{G}$ ). The toxicities of these CLEA-treated dye samples were significantly reduced. The HRP-CLEAs retained $60 \%$ of catalytic activity after seven cycles of methyl orange degradation.

Hollow CLEAs of laccase (h-CLEA laccase) were developed by using a millifluidic reactor [79]. Control of the solution flow rates in laminar flow enabled h-CLEA laccase particles of size $220 \pm 10 \mathrm{~nm}$ to be obtained. The activity of h-CLEA laccase was comparable to that of the free enzyme at neutral $\mathrm{pH}$, indicating that the laccase in the hollow structures had the same three-dimensional structure as free laccase. Uniformly sized h-CLEA laccase was trapped inside a disposable polyether sulfone membrane and continuously used for degradation of trypan blue for up to $96 \mathrm{~h}$ without loss of catalytic activity.

These studies indicate that improved CLEA techniques have great potential for industrial applications.

\subsubsection{Elimination of Endocrine-Disrupting Chemicals}

Endocrine-disrupting chemicals (EDCs) are defined as "exogenous chemical substances or mixtures that alter the structure or function(s) of the endocrine system and cause adverse effects at the level of the organism, its progeny, populations, or subpopulations of organisms, based on scientific principles, data, weight-of-evidence, and the precautionary principle" [80]. EDCs are often detected in industrial wastewaters. Oxidases such as laccase and peroxidase have been widely used for EDC degradation.

We developed a novel continuous-flow laccase-CEM for the degradation of EDCs [30]. Estrogens (E1, E2, and EE2) and anti-inflammatories (naproxen and diclofenac) were used as model EDCs for degradation studies. The degradation efficiency of our microreaction system was better than those of conventional bioreactors. Furthermore, it enabled two-step degradation in laccase-mediated reactions, thereby avoiding inactivation of laccase-CLEAs. Taboada-Puig et al. used combi-CLEAs containing peroxidase and glucose oxidase for degradation reactions [81]. The degradation of bisphenol A, nonylphenol, triclosan, EE2, and E2 by combi-CLEAs and their residual estrogenic activities were studied. Within $10 \mathrm{~min}$, the combi-CLEAs degraded almost all the EDCs except triclosan. The residual estrogenic activity was lower than $45 \%$ for all compounds, except triclosan. In addition, a continuous membrane reactor with combi-CLEAs almost completely removed bisphenol A $\left(10 \mathrm{mg} \mathrm{L}^{-1}\right)$ in $43 \mathrm{~h}$. These reports indicate that a CLEA-based continuous degradation system provides a simple catalytic system that can eliminate EDCs effectively.

\subsubsection{Bioconversion of Agroindustrial Waste}

The immobilized enzymatic bioconversion of lignocellulosic biomass such as SCB to biofuels is an important technology in the production of clean energy. Xylanase-CLEAs were prepared and used for SCB bioconversion [82]. The CLEAs produced xylo-oligosaccharides from SCB, whereas the free enzyme produced xylose as the main product from the same SCB. This indicates that immobilization modified the catalytic properties. Bhattacharya and Pletschke prepared magnetic xylanase-CLEAs for bioconversion of SCB to sugar [83]. They reported that the activity and stability of the magnetite-CLEAs and reusability of the CLEAs were enhanced; a higher hydrolysis yield was obtained from SCB.

\section{Conclusions}

Immobilized enzymes retain their catalytic activity and are more robust to environmental changes compared with free enzymes. The operational stability depends on the immobilization method. CLEAs were developed for carrier-free immobilization as an alternative to conventional immobilization on solid carriers and cross-linked enzyme crystals. CLEAs have several advantages over conventional 
methods, for example, simple preparation, high catalytic activity, high operational stability, and low production costs. Applications of CLEAs have therefore been widely investigated in various industries. There are still obstacles to the development of immobilized enzymes as biocatalysts for practical applications. As noted in this review, improved CLEA techniques will enable the development of novel enzymatic reaction systems. The development of new techniques will enable expansion of the industrial use of enzyme immobilization.

Author Contributions: Hiroshi Yamaguchi researched the literature and wrote the manuscript; Yuhei Kiyota and Masaya Miyazaki discussed ideas and edited the manuscript.

Funding: This research received no external funding.

Acknowledgments: Part of this work was supported by a Grant-in-Aid for Basic Scientific Research (C: 15K04639) from JSPS (H.Y.) and the Research and Study Program/Project of Tokai University Education System General Research Organization (H.Y.). We thank Helen McPherson, from Liwen Bianji, Edanz Editing China (www. liwenbianji.cn/ac), for editing the English text of a draft of this manuscript.

Conflicts of Interest: The authors declare no conflict of interest.

\section{References}

1. Madhavan, A.; Sindhu, R.; Binod, P.; Sukumaran, R.K.; Pandey, A. Strategies for design of improved biocatalysts for industrial applications. Bioresour. Technol. 2017, 245, 1304-1313. [CrossRef] [PubMed]

2. Sheldon, R.A.; Woodley, J.M. Role of biocatalysis in sustainable chemistry. Chem. Rev. 2018, 118, 801-838. [CrossRef] [PubMed]

3. Elleuche, S.; Schröder, C.; Sahm, K.; Antranikian, G. Extremozymes-Biocatalysts with unique properties from extremophilic microorganisms. Curr. Opin. Biotechnol. 2014, 29, 116-123. [CrossRef] [PubMed]

4. Sheldon, R.A. Characteristic features and biotechnological applications of cross-linked enzyme aggregates (CLEAs). Appl. Microbiol. Biotechnol. 2011, 92, 467-477. [CrossRef] [PubMed]

5. Franssen, M.C.; Steunenberg, P.; Scott, E.L.; Zuilhof, H.; Sanders, J.P. Immobilised enzymes in biorenewables production. Chem. Soc. Rev. 2013, 42, 6491-6533. [CrossRef] [PubMed]

6. Bilal, M.; Iqbal, H.M.N.; Guo, S.; Hu, H.; Wang, W.; Zhang, X. State-of-the-art protein engineering approaches using biological macromolecules: A review from immobilization to implementation view point. Int. J. Biol. Macromol. 2018, 108, 893-901. [CrossRef] [PubMed]

7. Miyazaki, M.; Portia Nagata, M.; Honda, T.; Yamaguchi, H. Bioorganic and biocatalytic reactions. In Microreactors in Organic Synthesis and Catalysis, 2nd ed.; Wiley-VCH: Hoboken, NJ, USA, 2013; Chapter 10.

8. Honda, T.; Yamaguchi, H.; Miyazaki, M. Development of enzymatic reactions in miniaturized reactors. In Innovations and Future Directions Applied Bioengineering; Wiley-VCH: Hoboken, NJ, USA, 2017; pp. 99-166.

9. Wang, L.S.; Khan, F.; Micklefield, J. Selective covalent protein immobilization: Strategies and applications. Chem. Rev. 2009, 109, 4025-4053. [CrossRef] [PubMed]

10. Asanomi, Y.; Yamaguchi, H.; Miyazaki, M.; Maeda, H. Enzyme-immobilized microfluidic process reactors. Molecules 2011, 16, 6041-6059. [CrossRef] [PubMed]

11. Yiu, H.H.P.; Wright, P.A. Enzymes supported on ordered mesoporous solids: A special case of an inorganic-organic hybrid. J. Mater. Chem. 2005, 15, 3690-3700. [CrossRef]

12. Cha, T.W.; Guo, A.; Zhu, X.Y. Enzymatic activity on a chip: The critical role of protein orientation. Proteomics 2005, 5, 416-419. [CrossRef] [PubMed]

13. Zaborsky, O.R. Immobilized Enzymes; CRC Press: Cleveland, OH, USA, 1973.

14. St. Clair, N.L.; Navia, M.A. Cross-linked enzyme crystals as robust biocatalysts. J. Am. Chem. Soc. 1992, 114, 7314-7316. [CrossRef]

15. Roy, J.J.; Abraham, T.E. Strategies in making cross-linked enzyme crystals. Chem. Rev. 2004, 104, 3705-3722. [CrossRef]

16. Cao, L.; van Langen, L.; Sheldon, R.A. Immobilised enzymes: Carrier-bound or carrier-free? Curr. Opin. Biotechnol. 2003, 14, 387-394. [CrossRef]

17. Shah, S.; Sharma, A.; Gupta, M.N. Preparation of cross-linked enzyme aggregates by using bovine serum albumin as a proteic feeder. Anal. Biochem. 2006, 351, 207-213. [CrossRef] [PubMed] 
18. Schoevaart, R.; Wolbers, M.W.; Golubovic, M.; Ottens, M.; Kieboom, A.P.; van Rantwijk, F.; van der Wielen, L.A.; Sheldon, R.A. Preparation, optimization, and structures of cross-linked enzyme aggregates (CLEAs). Biotechnol. Bioeng. 2004, 87, 754-762. [CrossRef] [PubMed]

19. Majumder, A.B.; Gupta, M.N. Stabilization of Candida rugosa lipase during transacetylation with vinyl acetate. Bioresour. Technol. 2010, 101, 2877-2879. [CrossRef] [PubMed]

20. Mateo, C.; Palomo, J.M.; van Langen, L.M.; van Rantwijk, F.; Sheldon, R.A. A new, mild cross-linking methodology to prepare cross-linked enzyme aggregates. Biotechnol. Bioeng. 2004, 86, 273-276. [CrossRef] [PubMed]

21. López-Gallego, F.; Betancor, L.; Hidalgo, A.; Alonso, N.; Fernández-Lafuente, R.; Guisán, J.M. Coaggregation of enzymes and polyethyleneimine: A simple method to prepare stable and immobilized derivatives of glutaryl acylase. Biomacromolecules 2005, 6, 1839-1842. [CrossRef] [PubMed]

22. Wilson, L.; Illanes, A.; Abián, O.; Pessela, B.C.; Fernández-Lafuente, R.; Guisán, J.M. Coaggregation of penicillin $g$ acylase and polyionic polymers: An easy methodology to prepare enzyme biocatalysts stable in organic media. Biomacromolecules 2004, 5, 852-857. [CrossRef] [PubMed]

23. Zheng, J.; Chen, Y.; Yang, L.; Li, M.; Zhang, J. Preparation of cross-linked enzyme aggregates of trehalose synthase via coaggregation with polyethyleneimine. Appl. Biochem. Biotechnol. 2014, 174, 2067-2078. [CrossRef] [PubMed]

24. Zhang, Y.; Ren, H.; Wang, Y.; Chen, K.; Fang, B.; Wang, S. Bioinspired immobilization of glycerol dehydrogenase by metal ion-chelated polyethyleneimines as artificial polypeptides. Sci. Rep. 2016, 6, 24163. [CrossRef] [PubMed]

25. Honda, T.; Miyazaki, M.; Nakamura, H.; Maeda, H. Immobilization of enzymes on a microchannel surface through cross-linking polymerization. Chem. Commun. 2005, 40, 5062-5064. [CrossRef] [PubMed]

26. Honda, T.; Miyazaki, M.; Nakamura, H.; Maeda, H. Facile preparation of an enzyme-immobilized microreactor using a cross-linking enzyme membrane on a microchannel surface. Adv. Synth. Catal. 2006, 348, 2163-2171. [CrossRef]

27. Honda, T.; Miyazaki, M.; Yamaguchi, Y.; Nakamura, H.; Maeda, H. Integrated microreaction system for optical resolution of racemic amino acids. Lab Chip 2007, 7, 366-372. [CrossRef] [PubMed]

28. Yamaguchi, H.; Miyazaki, M.; Maeda, H. Proteolysis approach without chemical modification for a simple and rapid analysis of disulfide bonds using thermostable protease-immobilized microreactors. Proteomics 2010, 10, 2942-2949. [CrossRef] [PubMed]

29. Yamaguchi, H.; Miyazaki, M.; Kawazumi, H.; Maeda, H. Multidigestion in continuous flow tandem protease-immobilized microreactors for proteomic analysis. Anal. Biochem. 2010, 407, 12-18. [CrossRef] [PubMed]

30. Lloret, L.; Eibes, G.; Moreira, M.T.; Feijoo, G.; Lema, J.M.; Miyazaki, M. Improving the catalytic performance of laccase using a novel continuous-flow microreactor. Chem. Eng. J. 2013, 223, 497-506. [CrossRef]

31. Yamaguchi, H.; Miyazaki, M.; Asanomi, Y.; Maeda, H. Poly-lysine supported cross-linked enzyme aggregates with efficient enzymatic activity and high operational stability. Catal. Sci. Technol. 2011, 1, 1256-1261. [CrossRef]

32. Theil, F. Enhancement of selectivity and reactivity of lipases by additives. Tetrahedron 2000, 56, $2905-3076$. [CrossRef]

33. Gupta, P.; Dutt, K.; Misra, S.; Raghuwanshi, S.; Saxena, R.K. Characterization of cross-linked immobilized lipase from thermophilic mould Thermomyces lanuginosa using glutaraldehyde. Bioresour. Technol. 2009, 100, 4074-4076. [CrossRef] [PubMed]

34. Fernández-Lorente, G.; Palomo, J.M.; Mateo, C.; Munilla, R.; Ortiz, C.; Cabrera, Z.; Guisán, J.M.; Fernandez-Lafuente, R. Glutaraldehyde cross-linking of lipases adsorbed on aminated supports in the presence of detergents leads to improved performance. Biomacromolecules 2006, 7, 2610-2615. [CrossRef] [PubMed]

35. De Rose, S.A.; Novak, H.; Dowd, A.; Singh, S.; Lang, D.A.; Littlechild, J. Stabilization of a lipolytic enzyme for commercial application. Catalysts 2017, 7, 91. [CrossRef]

36. Burhan, A.; Nisa, U.; Gökhan, C.; Ömer, C.; Ashabil, A.; Osman, G. Enzymatic properties of a novel thermostable, thermophilic, alkaline and chelator resistant amylase from an alkaliphilic Bacillus sp. isolate ANT-6. Process Biochem. 2003, 38, 1397-1403. [CrossRef] 
37. Torabizadeh, H.; Tavakoli, M.; Safari, M. Immobilization of thermostable $\alpha$-amylase from Bacillus licheniformis by cross-linked enzyme aggregates method using calcium and sodium ions as additives. J. Mol. Catal. B: Enzym. 2014, 108, 13-20. [CrossRef]

38. Khorshidi, K.J.; Lenjannezhadian, H.; Jamalan, M.; Zeinali, M. Preparation and characterization of nanomagnetic cross-linked cellulase aggregates for cellulose bioconversion. J. Chem. Technol. Biotechnol. 2016, 91, 539-546. [CrossRef]

39. Dalal, S.; Sharma, A.; Gupta, M.N. A multipurpose immobilized biocatalyst with pectinase, xylanase and cellulase activities. Chem. Cent. J. 2007, 1, 16. [CrossRef] [PubMed]

40. Nguyen, L.T.; Yang, K.L. Uniform cross-linked cellulase aggregates prepared in millifluidic reactors. J. Colloid Interface Sci. 2014, 428, 146-151. [CrossRef] [PubMed]

41. Perzon, A.; Dicko, C.; Çobanoğlu, Ö.; Yükselen, O.; Eryilmaz, J.; Dey, E.S. Cellulase cross-linked enzyme aggregates (CLEA) activities can be modulated and enhanced by precipitant selection. J. Chem. Technol. Biotechnol. 2017, 92, 1645-1649. [CrossRef]

42. Devi, B.L.A.P.; Guo, Z.; Xu, X. Characterization of cross-linked lipase aggregates. J. Am. Oil Chem. Soc. 2009, 86, 637-642. [CrossRef]

43. Rehman, S.; Bhatti, H.N.; Bilal, M.; Asgher, M. Cross-linked enzyme aggregates (CLEAs) of Pencilluim notatum lipase enzyme with improved activity, stability and reusability characteristics. Int. J. Biol. Macromol. 2016, 91, 1161-1169. [CrossRef] [PubMed]

44. Chen, Y.; Xiao, C.; Chen, X.; Yang, L.; Qi, X.; Zheng, J.; Li, M.; Zhang, J. Preparation of cross-linked enzyme aggregates in water-in-oil emulsion: Application to trehalose synthase. J. Mol. Catal. B: Enzym. 2014, 100, 84-90. [CrossRef]

45. Verheyen, E.; Schillemans, J.P.; van Wijk, M.; Demeniex, M.A.; Hennink, W.E.; van Nostrum, C.F. Challenges for the effective molecular imprinting of proteins. Biomaterials 2011, 32, 3008-3020. [CrossRef] [PubMed]

46. Fishman, A.; Coganb, U. Bio-imprinting of lipases with fatty acids. J. Mol. Catal. B: Enzym. 2003, 22, $193-202$. [CrossRef]

47. Cabirol, F.L.; Tan, P.L.; Tay, B.; Cheng, S.; Hanefeld, U.; Sheldon, R.A. Linum usitatissimum Hydroxynitrile lyase cross-linked enzyme aggregates: A recyclable enantioselective catalyst. Adv. Synth. Catal. 2008, 350, 2329-2338. [CrossRef]

48. De Winter, K.; Soetaert, W.; Desmet, T. An imprinted cross-linked enzyme aggregate (iCLEA) of sucrose phosphorylase: Combining improved stability with altered specificity. Int. J. Mol. Sci. 2012, 13, 11333-11342. [CrossRef] [PubMed]

49. Sampath, C.; Belur, P.D.; Iyyasami, R. Enhancement of n-3 polyunsaturated fatty acid glycerides in Sardine oil by a bioimprinted cross-linked Candida rugosa lipase. Enzyme Microb. Technol. 2018, 110, 20-29. [CrossRef] [PubMed]

50. Cao, L. Immobilised enzymes: Science or art? Curr. Opin. Chem. Biol. 2005, 9, 217-226. [CrossRef] [PubMed]

51. Kim, M.I.; Kim, J.; Lee, J.; Jia, H.; Na, H.B.; Youn, J.K.; Kwak, J.H.; Dohnalkova, A.; Grate, J.W.; Wang, P.; et al. Crosslinked enzyme aggregates in hierarchically-ordered mesoporous silica: A simple and effective method for enzyme stabilization. Biotechnol. Bioeng. 2007, 96, 210-218. [CrossRef] [PubMed]

52. Wang, M.; Qi, W.; Yu, Q.; Su, R.; He, S. Cross-linking enzyme aggregates in the macropores of silica gel: A practical and efficient method for enzyme stabilization. Biochem. Eng. J. 2010, 52, 168-174. [CrossRef]

53. Cui, J.D.; Li, L.L.; Bian, H.J. Immobilization of cross-linked phenylalanine ammonia lyase aggregates in microporous silica gel. PLoS ONE 2013, 8, e80581. [CrossRef] [PubMed]

54. Jiang, Y.; Shi, L.; Huang, Y.; Gao, J.; Zhang, X.; Zhou, L. Preparation of robust biocatalyst based on cross-linked enzyme aggregates entrapped in three-dimensionally ordered macroporous silica. ACS Appl. Mater. Interfaces 2014, 6, 2622-2628. [CrossRef] [PubMed]

55. Talekar, S.; Ghodake, V.; Ghotage, T.; Rathod, P.; Deshmukh, P.; Nadar, S.; Mulla, M.; Ladole, M. Novel magnetic cross-linked enzyme aggregates (magnetic CLEAs) of alpha amylase. Bioresour. Technol. 2012, 123, 542-547. [CrossRef] [PubMed]

56. Sekhon, S.S.; Ahn, J.-Y.; Shin, W.-R.; Ko, J.H.; Lee, L.; Dawes, M.; Tyler, J.; Han, J.; Kim, S.Y.; Min, J.; Kim, Y.-H. Immobilization of cross-linked cutinase aggregates onto magnetic beads for degradation of polycaprolactone. J. Nanosci. Nanotechnol. 2017, 17, 9306-9311. [CrossRef]

57. Liu, Y.; Guo, C.; Liu, C.-Z. Novel magnetic cross-linked lipase aggregates for improving the resolution of $(R, S)-2-o c t a n o l$. Chirality 2015, 27, 199-204. [CrossRef] [PubMed] 
58. Xu, D.-Y.; Yang, Z. Cross-linked tyrosinase aggregates for elimination of phenolic compounds from wastewater. Chemosphere 2013, 92, 391-398. [CrossRef] [PubMed]

59. Nguyen, L.T.; Lau, Y.S.; Yang, K.L. Entrapment of cross-linked cellulase colloids in alginate beads for hydrolysis of cellulose. Colloids Surf. B Biointerfaces. 2016, 145, 862-869. [CrossRef] [PubMed]

60. Mateo, C.; Chmura, A.; Rustler, S.; van Rantwijk, F.; Stolz, A.; Sheldon, R.A. Synthesis of enantiomerically pure (S)-mandelic acid using an oxynitrilase-nitrilase bienzymatic cascade: A nitrilase surprisingly shows nitrile hydratase activity. Tetrahedron Asymm. 2006, 17, 320-323. [CrossRef]

61. Talekar, S.; Pandharbale, A.; Ladole, M.; Nadar, S.; Mulla, M.; Japhalekar, K.; Pattankude, K.; Arage, D. Carrier free coimmobilization of alpha amylase, glucoamylase and pullulanase as combined cross-linked enzyme aggregates (combi-CLEAs): A tri-enzyme biocatalyst with one pot starch hydrolytic activity. Bioresour. Technol. 2013, 147, 269-275. [CrossRef] [PubMed]

62. Periyasamy, K.; Santhalembi, L.; Mortha, G.; Aurousseau, M.; Subramanian, S. Carrier-free coimmobilization of xylanase, cellulase and $\beta$-1,3-glucanase as combined crosslinked enzyme aggregates (combi-CLEAs) for one-pot saccharification of sugarcane bagasse. RSC Adv. 2016, 6, 32849-32857. [CrossRef]

63. Ning, C.; Su, E.; Tian, Y.; Wei, D. Combined cross-linked enzyme aggregates (combi-CLEAs) for efficient integration of a ketoreductase and a cofactor regeneration system. J. Biotechnol. 2014, 184, 7-10. [CrossRef] [PubMed]

64. Su, E.; Meng, Y.; Ning, C.; Ma, X.; Deng, S. Magnetic combined cross-linked enzyme aggregates (combi-CLEAs) for cofactor regeneration in the synthesis of chiral alcohol. J. Biotechnol. 2018, 271, 1-7. [CrossRef] [PubMed]

65. Nguyen, L.T.; Yang, K.L. Combined cross-linked enzyme aggregates of horseradish peroxidase and glucose oxidase for catalyzing cascade chemical reactions. Enzyme Microb. Technol. 2017, 100, 52-59. [CrossRef] [PubMed]

66. Jung, D.-H.; Jung, J.-H.; Seo, D.-H.; Ha, S.-J.; Kweon, D.-K.; Park, C.-S. One-pot bioconversion of sucrose to trehalose using enzymatic sequential reactions in combined cross-linked enzyme aggregates. Bioresour. Technol. 2013, 130, 801-804. [CrossRef] [PubMed]

67. Scism, R.A.; Bachmann, B.O. Five-component cascade synthesis of nucleotide analogues in an engineered self-immobilized enzyme aggregate. ChemBioChem 2010, 11, 67-70. [CrossRef] [PubMed]

68. Mahmod, S.S.; Yusof, F.; Jami, M.S.; Khanahmadi, S.; Shah, H. Development of an immobilized biocatalyst with lipase and protease activities as a multipurpose cross-linked enzyme aggregate (multi-CLEA). Process Biochem. 2015, 50, 2144-2157. [CrossRef]

69. Chen, Z.; Wang, Y.; Liu, W.; Wang, J.; Chen, H. A novel cross-linked enzyme aggregates (CLEAs) of papain and neutrase-production, partial characterization and application. Int. J. Biol. Macromol. 2017, 95, 650-657. [CrossRef] [PubMed]

70. Hickey, A.M.; Ngamsom, B.; Wiles, C.; Greenway, G.M.; Watts, P.; Littlechild, J.A. A microreactor for the study of biotransformations by a cross-linked $\gamma$-lactamase enzyme. Biotechnol. J. 2009, 4, 510-516. [CrossRef] [PubMed]

71. Lanfranchi, E.; Grill, B.; Raghoebar, Z.; Van Pelt, S.; Sheldon, R.A.; Steiner, K.; Glieder, A.; Winkler, M. Production of hydroxynitrile lyase from $D$. tyermannii $(D t \mathrm{HNL})$ in Komagataella phaffii and its immobilization as a CLEA to generate a robust biocatalyst. ChemBioChem 2018, 19, 312-316. [CrossRef] [PubMed]

72. Xu, D.-Y.; Chen, J.-Y.; Yang, Z. Use of cross-linked tyrosinase aggregates as catalyst for synthesis of L-DOPA. Biochem. Eng. J. 2012, 63, 88-94. [CrossRef]

73. Nuijens, T.; Cusan, C.; Schepers, A.C.H.M.; Kruijtzer, J.A.W.; Quaedflieg, P.J.L.M. Enzymatic synthesis of activated esters and their subsequent use in enzyme-based peptide synthesis. J. Mol. Catal. B: Enzym. 2011, 71, 79-84. [CrossRef]

74. Stavila, E.; Alberda van Ekenstein, G.R.O.; Loos, K. Enzyme-catalyzed synthesis of aliphatic-aromatic oligoamides. Biomacromolecules 2013, 14, 1600-1606. [CrossRef] [PubMed]

75. Talekar, S.; Joshi, A.; Chougle, R.; Nakhe, A.; Bhojwani, R. Immobilized enzyme mediated synthesis of silver nanoparticles using cross-linked enzyme aggregates (CLEAs) of NADH-dependent nitrate reductase. Nano-Struct. Nano-Objects. 2016, 6, 23-33. [CrossRef]

76. Forootanfar, H.; Faramarzi, M.A. Insights into laccase producing organisms, fermentation states, purification strategies, and biotechnological applications. Biotechnol. Prog. 2015, 31, 1443-1463. [CrossRef] [PubMed] 
77. Kumar, V.V.; Sivanesan, S.; Cabana, H. Magnetic cross-linked laccase aggregates-Bioremediation tool for decolorization of distinct classes of recalcitrant dyes. Sci. Total Environ. 2014, 487, 830-839. [CrossRef] [PubMed]

78. Bilal, M.; Iqbal, H.M.N.; Hu, H.; Wang, W.; Zhang, X. Development of horseradish peroxidase-based cross-linked enzyme aggregates and their environmental exploitation for bioremediation purposes. J. Environ. Manag. 2017, 188, 137-143. [CrossRef] [PubMed]

79. Nguyen, L.T.; Seow, N.; Yang, K.-L. Hollow cross-linked enzyme aggregates (h-CLEA) of laccase with high uniformity and activity. Colloids Surf. B Biointerfaces. 2017, 151, 88-94. [CrossRef] [PubMed]

80. Special Report on Environmental Endocrine Disruption: An Effects Assessment and Analysis. 1997. Available online: https://archive.epa.gov/raf/web/html/special-rpt-endocrine-disruption.html (accessed on 8 February 2018).

81. Taboada-Puig, R.; Junghanns, C.; Demarche, P.; Moreira, M.T.; Feijoo, G.; Lema, J.M.; Agathos, S.N. Combined cross-linked enzyme aggregates from versatile peroxidase and glucose oxidase: Production, partial characterization and application for the elimination of endocrine disruptors. Bioresour. Technol. 2011, 102, 6593-6599. [CrossRef] [PubMed]

82. Hero, J.S.; Romero, C.M.; Pisa, J.H.; Perotti, N.I.; Olivaro, C.; Martinez, M.A. Designing cross-linked xylanase aggregates for bioconversion of agroindustrial waste biomass towards potential production of nutraceuticals. Int. J. Biol. Macromol. 2018, 111, 229-236. [CrossRef] [PubMed]

83. Bhattacharya, A.; Pletschke, B.I. Magnetic cross-linked enzyme aggregates (CLEAs): A novel concepttowards carrier free immobilization of lignocellulolytic enzymes. Enzyme Microb. Technol. 2014, 61-62, 17-27. [CrossRef] [PubMed]

(C) 2018 by the authors. Licensee MDPI, Basel, Switzerland. This article is an open access article distributed under the terms and conditions of the Creative Commons Attribution (CC BY) license (http:/ / creativecommons.org/licenses/by/4.0/). 